\title{
Article
}

\section{Psychosocial Research Analysis and Scenic understanding}

Froggett, Lynn and Hollway, Wendy

Available at http://clok.uclan.ac.uk/3334/

Froggett, Lynn ORCID: 0000-0001-8406-6231 and Hollway, Wendy (2010) Psychosocial Research Analysis and Scenic understanding. Psychoanalysis, Culture and Society, 15 (3). pp. 281-301. ISSN 1088-0763

It is advisable to refer to the publisher's version if you intend to cite from the work. http://dx.doi.org/10.1057/pcs.2010.18

For more information about UCLan's research in this area go to http://www.uclan.ac.uk/researchgroups/ and search for < name of research Group>.

For information about Research generally at UCLan please go to http://www.uclan.ac.uk/research/

All outputs in CLoK are protected by Intellectual Property Rights law, including Copyright law. Copyright, IPR and Moral Rights for the works on this site are retained by the individual authors and/or other copyright owners. Terms and conditions for use of this material are defined in the policies page.

\section{CLoK}

Central Lancashire online Knowledge www.clok.uclan.ac.uk 
Original article

Froggett, L. \& Hollway, W. (2010) Psychosocial Research Analysis and Scenic Understanding. Psychoanalysis, Culture and Society, 15(3), 281-301.

Lynn Froggett

Psychosocial Research Unit, International School for Communities, Rights and Inclusion, Harrington Building, University of Central Lancashire, Preston, PR1 2HE, UK.

Email: Ifroggett@uclan.ac.uk

\section{Wendy Hollway}

Psychology Department, Open University, Walton Hall, Milton Keynes, MK7 6AA, UK.

Email: w.hollway@open.ac.uk

Abstract In this paper two researchers who position themselves within an emergent psychosocial current in the UK apply the concept to a segment of film footage of an interaction (part of an empirical qualitative research project) to explore what Alfred Lorenzer's theory of scenic understanding can add to our existing methodological resources. The film footage shows the creation of a poem by Darren, a 16-year-old offender, and Bob, a local poet employed in a project investigating the rehabilitative potential of one-to-one creative writing sessions. The authors contrast the transcript of this encounter with a 'scenic composition', a device they developed to communicate to a research readership the scenic experience of watching a filmed interaction. This contrast forms the basis for bringing together a series of post-Kleinian ideas about modes of knowing (syncretistic perception, reverie, transitional space) with Lorenzer's scenic understanding. Through the idea of provocations in the text, the authors focus on the researcher's emotional experience to explore the psychosocial character of the meanings that emerge concerning Darren's claim, 'I'm not clever', and how these meanings are communicated amongst Darren, Bob and the researcher. Through the lens of symbolised and unsymbolised emotional experience, play and triangular space, the authors consider Darren's ambivalent relationship to the creative writing activity and conclude with a short discussion of 
the conceptualisation of unconscious processes suitable to a psychosocial data analytic methodology.

Keywords: Lorenzer; scenic understanding; interaction forms; psychosocial method ; experience-near; symbolisation

\section{Psychosocial research analysis and scenic understanding}

\section{Introduction}

In this article we explore Lorenzer's idea of scenic understanding in the context of psychosocial research methodology by bringing it into dialogue with concepts from the British post-Kleinian tradition. Our primary aim is to transpose the concept of scenic understanding from Lorenzer's (1986) cultural analysis to the analysis of data produced in psychosocial research. Our psychosocial approach means that we want to learn from Lorenzer's way of articulating psychological and societal-cultural processes together in a way that avoids dualism.

The material is drawn from research undertaken with a Youth Offending Team (YOT) in the North of England1 that aimed to investigate the rehabilitative potential of creative writing sessions conducted on a one-to-one basis by a local poet with young offenders. The project as a whole has been documented elsewhere (Farrier et al, 2009) and includes two case studies in the British psychosocial tradition (Froggett, 2007; Froggett et al, 2007) and a theorisation of the use of artistic media as an intersubjective third that draws on relational psychoanalysis (Froggett, 2008).

Participants were offered a series of sessions with Bob, a local poet, who enabled them to talk about their lives, relationships and offending while he wrote down their words and helped to craft them into a poem. A fixed camera was set up in the corner of the cramped little office that served as a poetry room. After the participants had been introduced to both the camera and the researchers, the researchers withdrew and the sessions were filmed. The young people were subsequently asked to participate in biographical narrative interviews, and the data were aggregated.

Darren, aged 16, is one of the young offenders who comes in to the poetry room from the workshop next door, where young men were building go-karts under the supervision of Al, the workshop manager. We know from an interview with Darren that he has been excluded 
from school - as he said 'for being racist mostly' (see below). On the film he looks uncomfortable with the process and seems to hover between staying and going. When asked to read the completed poem, he says he can't read. He looks pleased as he listens to Bob reading it, then abruptly leaves the room.

That account is taken mainly from a film record of the session between Darren and Bob, but it refers to background information acquired by interview and other Youth Offending team records. Film-based data do not simply present an enactment of a script where we can see the paralinguistic elements of body language. Something qualitatively different is evoked when one watches a recording of a live situation. The entire subjective understanding of the researcher (understood as reflexivity within qualitative research) is at stake in analysing research data. This recognition has led us to ask what different forms of attention, interpretation, imaginative association, affect and cognition are required for converting the observational experience into language in a way that can be communicated to others.

The creative writing session, including the camera and earlier presence of the researcher, together constitute what, for Lorenzer, is a scene in the present, one that requires a certain kind of method for its apprehension (for a fuller account, see Bereswill et al, this issue). Lorenzer (1977) writes: '[I]f we want to understand the analysand's life practice, including his concrete social reality, we must follow the path laid down by his subjective ideas and fantasies about relations. [Along this path] we must become attuned to his scenic interaction forms as these unfold before us' (p. 125). As this statement suggests, current interactions contain interaction forms from the past (symbolised and otherwise) and together these can potentially constitute a new interaction form. Such forms "lie between the "inside" and the "outside"' and 'their interplay accounts for everything' (Lorenzer, 1986, pp. 41-44). We understand this to mean that, in any given situation, scenic experience arises at the conjunction of biographically and dispositionally specific interactive patterns particular to the individual (for example, Darren's discomfort with written language), cultural patterns (for example, anxiety relating to the educational failure of young men like Darren) and the manifest forms of cultural life (systems and practices for the rehabilitation of educationally excluded youth). 
Action is influenced by recognisable cultural tropes and patterns that are available to social analysis, but that are, according to Lorenzer, also manifest in the unconscious memory traces that inflect the ways in which these tropes and patterns are enacted. Scenic understanding renders intelligible these personal configurations of societal-collective forms that influence action, together with the interaction forms that stir the not-yet-conscious experience of the researcher and emerge as 'provocations' (for example, Darren's teetering on the verge of flight) that attract attention and demand explanation. For a psychosocial analysis, the importance of Lorenzer's concept of scenic interaction forms is that the social is to be found not just 'out there' but within, and in unconscious, not yet symbolised, emotional experience, as well as in conscious knowledge.

Starting from the proposition that in the psychoanalytic process, all understanding centres on, and is related to, the mode of scenic understanding' (Lorenzer, 1977, p. 125), one of Lorenzer's primary concerns as a cultural analyst was to explore the implications of this premise for the analysis of texts. We have found it useful to think of the scene through a theatrical metaphor because doing so illuminates the status of the scene as a complex of actors, actions, setting, meanings and intentions that must be grasped as a whole. The manifest action is an enactment of a matrix of relations - some explicit, others merely hinted or present as unrealised potentials. Insofar as it lies between the watching audience (in our case, the research team) and a complex reality of which they are part, the scene is emblematic of the relations between them. In understanding the scene, we do not separate cognition, inference and affect as we achieve a personalised and emotionally resonant interpretation; we experience it as a whole. Often these processes take place below conscious awareness as we engage with the flow of the play. For each member of the audience (or research team), its reception is filtered through emotional, intellectual and aesthetic responses that configure in biographically specific patterns. These are mobilised to bear on their experience of the scene, which is intelligible as a common cultural object.

The methodological implications of this argument are explored in what follows by way of a 'scenic composition'2 arising from the primarily film-based data that we have already summarised briefly. We have invented this idea, following Lorenzer's concept of the scenic, so as to formulate an emotionally resonant complex whole and present it to readers. This does 
not mean that we are doing a Lorenzerian analysis. Rather, we are exploring what the idea of the scenic evokes and opens up in our own thought, which has been formed in what is now known as the British psychosocial research tradition.3 Part of the excitement has been the encounter between Lorenzer's concept of the scenic and theoretical ideas that were already proving productive, methodologically as well as ontologically, in analysing the visual qualities of film-based data; these ideas derived principally from the work of Anton Ehrenzweig (1967), Donald Winnicott (1971) and Wilfred Bion (1962, 1970), all working in a post-Kleinian tradition. We present the scenic composition after the transcript of the interaction that it describes.

\section{The Transcript}

In the following transcript produced from the film footage, Bob has started with his usual opener, which asks Darren to say three things about himself. One of these is that he is 'not clever':

Bob: What makes you say you're not clever?

Darren: [shrugs] I dunno ... you just do it for me ...

B: [shrugs] ... Why do you shrug [inaudible]

D: [shrugs] I dunno. Just a thing I do

B: Come on man, why aren't you clever? What's clever? Am I clever?

D: Yeah

B: Why?

D: 'Cos you can do poems and that. You're not clever biting your nails though. D'you bite your nails?

B: No

D: Yeah you do!

B: I don't

D: What is up with ...

B: I do that [bites thumb in detachable thumb visual gag]

D: [inaudible] other thumb [laughs] 
B: Clever people don't bite nails?

D: No

B: [inaudible] clever people do? Give me ... tell me of three clever people you know ...anyone ... mum, teachers ...

D: Yeah, mum

B: Anyone, anyone

D: Mum ...you [laughs]

B: One more.

D: Al

B: Al in there? [points to other room]

D: $\mathrm{Hmmm}$

B: Right, why's your mum clever?

D: [exasperatedly] Ohhhhh ...

B: Just ... one line!

D: 'Cos she is. She tells me what to do ... I don't know

B: Why am I clever?

D: 'Cos you can do poems and that

B: Why is Al clever?

D: I don't know...'Cos of his money...I dunno [inaudible]

B: But you're not clever? Is that what you think?

D: No

B: D'you think you'll be clever one day? Yeh [Darren nods.] And when you're not clever what will you be?

D: When I'm whaa ...?

B: When you're ... when you're clever, what will you be? 
D: Buzzin' me tits off4 [smiles] [Bob laughs; Darren stands up smiling]

B: Right, you gotta read this out!

D: I'm not reading that out! I can't read!

B: [reads] I don't know,

It's just a thing I do

Clever people bite their nails

Mum's clever, like you

Al's clever, I don't know why

I'm not clever

But not forever

I'll be buzzin' me tits off!

D: [walks to door] Not bad

B: What do you think of that? Does it work?

D: Yeah

An accurate transcription is something on which empirical qualitative research has traditionally depended: it can help us to avoid the dangers of relying on the researcher's construction of what transpired. Nonetheless, we think that a great deal is lost in this form of representation. In qualitative social science, transcript has come to represent the closest possible approximation of unmediated evidence, such that even researchers who adopt a poststructuralist scepticism about the nature of truth and reality tend to see it as the most reliable basis for data analysis. We think, rather, that it should be regarded as one of a number of ways - all of them mediated - of approaching good-enough understanding. The strengths of each mode can be then made transparent and preferably used in tandem.

In our view, the scenic composition that follows captures the affective qualities of the original encounter in ways that preserve 'experience nearness' (Geertz, 1974) for those who study the data later on. It is an attempt to find a device that renders the experience of the participants through the researcher's own experience of the scene observed on film. Seeing a 
film of an interaction in a setting is very different from the visualisation of that scene when interview texts are analysed. The multisensory information makes everything seem more immediate. The presence of the key actors appears to contract the sense of researcher distance, leaving an initial impression that there is less scope for interpretation. The emotional and sensory 'bombardment' intensifies problems of reflexivity. It is important, therefore, to find some way of representing the whole as a psychosocially contextualised totality of relations and actions without losing the observer's experience of physical presence. Meanwhile, the sheer quantity of data available in each short clip makes the equivalent of line-by-line analysis (common in text interpretation) so laborious as to be impracticable except for a very few short extracts. The scenic composition, then, is an attempt to represent the details of interaction within the embodied emotional texture of the whole. Although it is based on an extract from a longer interaction, it depicts a complex of relations rather than a moment in time or a single event. In this sense it represents a whole, consistent with Lorenzer's conception of a scene.

\section{A Scenic Composition}

This is Lynn's scenic composition based on the interaction just transcribed.

Darren is sitting uncomfortably beside Bob in the small, cramped office. The camera filming the scene is in front of them, and behind there is an untidy notice board on the wall. Beyond the closed door can be heard the commotion of the workshop where local kids are messing about with go-carts. Darren seems happy enough to have a go at poetry as long as Bob does the writing.

Darren is pale, gangly, shaven headed; slouchy shoulders in slouchy, street-cool clothes. He keeps his jacket on, collar up and hands deep in pockets. Yet he is childlike - waiting to be led, or entertained, or told what to do. His feet shuffle as if they don't quite belong to him and he is trying to find a place to store them. Speech comes in one-liners, mumbles and grunts. His talk seems as awkward as his feet - not quite part of him. He rubs his head as if it hurts when he is asked to think. His body says a lot though - never still for long, moving back and forth; and his eyes wander round the room. The office is not his element, but he is sticking with it.

Bob is fortyish, solid, loud, self-assured, a cool uncle figure who is believable because he knows the street - he's been there himself. He can listen but also fools around, plays with rap 
and fires questions. He provokes and gets away with it, but he has to work hard to get words out of Darren.

Bob asks Darren to tell him three things about himself. Darren says, 'I'm not clever'. Bob asks him why he thinks he isn't clever. Darren shrugs. (He shrugs at most things.) Bob asks, 'Am I clever?'. Darren shrugs again. Then, partly irritated, partly interested, he makes a move, 'You're not clever biting your nails though'. The tables are turned and Bob is brought down to size - kids bite their nails. Bob plays along with a silly thumb trick and puts his hand on Darren's arm. Darren leans back and grins. Now they're on a level, in tune, laughing. They can get to work.

Bob has his notebook and asks Darren to name three people he thinks are clever: 'Mum 'cos she tells me what to do, you 'cos you write poems' and Al'. Bob is pushing him now, 'Why aren't you clever ... ?' Darren rubs his head, stressed, but he's still there. He shoves his hand down his trousers - not cool and hard, just holding on for comfort. But between the questions and the banter a poem is taking shape, made up of Darren's words. He catches sight of the camera. He looks thoughtful, becomes self-conscious; eyes roll, lips press together. Then he grins. Shoulders drop, face lights up - those are his words that Bob is stringing together with style.

'Do you think you'll be clever one day?' All of a sudden Bob stumbles, 'And when you're not clever what will you be?' Darren is onto him, 'When I'm whaaa ... ?'. 'I mean when you're clever ...' Darren is defiant now and pleased. He stands up, 'I'll be buzzing me tits off'. But he panics when asked to read the poem: 'I'm not reading that, I can't read'. Darren is still on his feet, fascinated yet poised for flight. For a moment he looks down on Bob, still sitting with the poem composed from Darren's words. Will he stay long enough to hear it? Bob raises his voice, quickens the pace, jabs the air with his finger, reads the poem:

It's just a thing I do

Clever people bite their nails

Mum's clever, like you

Al's clever, I don't know why

I'm not clever 


\section{But not forever}

I'll be buzzin' me tits off!

'Does it work?' 'Yeah'. Then he's gone.

Qualitative social scientists now acknowledge that every stage of empirical research, from choice of method through data analysis to writing up, is mediated by the researchers' own meaning-making processes. Consequently, a crucial methodological question is how to achieve experience nearness without compromising validity (Hollway, 2009). The production of this scenic composition clearly relies on Lynn's subjective experience of the encounter between Darren and Bob. It is also informed by everything else she knows about Darren from the interview conducted with him and from other data compiled by professionals and held on file.5 How does a researcher reflexively generate this scenic mode of data representation?

Here is how Lynn described her approach to writing the scenic composition:

I have to leave aside the work of analysis and take distance from the object - usually by waiting a period of time and allowing an unconscious processing of the material to take place. I write the account 'as it comes', when I feel ready, after a period of something like 'reverie', and without re-visiting the analytic material. I find that a scenic structure emerges and although I may later compare and craft the details, the principles of selection and organisation are affectively and aesthetically driven and are unlikely to change. The resulting composition conveys the 'feel' of the interaction as I experience it. It is partly a product of my own association and unconscious phantasy.

Those few lines draw on a rich range of psychoanalytic ideas, some basic, like unconscious processing, phantasy and association, some more specific, like Wilfred Bion's concept of reverie. Our engagement with psychoanalysis, especially in relation to creativity and the aesthetic faculty (Ehrenzweig, 1967; Winnicott, 1971), together with the role of emotional experience in thinking and learning (Bion, 1962, 1967, 1970), had already turned our attention to the importance of respecting the feeling in language. Without this, language is stripped of meaning, and our experience - as readers of research data and research writing - is denuded of 
vividness and significance. The scenic composition is intended to express an aesthetic appreciation of the scene rendered in language stylistically adequate to that particular scene and no other. It tries to capture the anxieties and irritations of the encounter, the street style of Darren's presentation and posture, the awkwardness in mannerisms, the rhythms of speech and gesture. All these convey, through Lynn's apprehension, what Christopher Bollas (1989, 1992) would call 'personal idiom'; we might call this the 'Darrenness' of Darren, whereby he leaves a distinctive impression or 'existential signature' that is registered by the people who encounter him. The writing both relies on and transmits an affective response that is not wholly conscious and depends on a receptive attunement to the qualities of the individual and the encounter.

In thinking about the kind of receptivity at play when we respond to the distinctive aesthetic qualities of a scene, we had previously turned to the work of the art critic and psychoanalyst Anton Ehrenzweig (1967). Ehrenzweig was a contemporary of Winnicott's, with whom he shared an interest in the development of a psychoanalytically informed account of creativity. Like Lorenzer, they were interested in how we apprehend cultural objects, specifically in the relation between the creative associations of primary process, open (or 'evenly hovering') attention and the production or appreciation of art and culture. Ehrenzweig understood artistic perception as a creative attempt to comprehend complex wholes, summed up in his account of syncretism. According to Ehrenzweig, syncretistic perception is achieved through a form of scanning that depends on a relaxation of cognitive focus and allows a response driven by primary process - it is through syncretism that a personalised and embodied aesthetic appreciation is brought to bear on the object.

In contrast, the work of analysis depends on the ego and the deconstructive and reorganising functions of the intellect. Syncretism and analysis afford qualitatively different views of the object: whereas analysis is essential for identifying the components of a complex structure and for a relatively detached and dispassionate stance, syncretism depends on a necessarily subjective experience that brings one closer to the object and is better able to afford an appreciation of the relations that compose the whole, relations that in their complexity and ambiguity are likely to elude consciously directed attention. The idea is developed from a Kleinian epistemology in which the kind of knowledge afforded by a 
depressive relation to reality allows the object to reveal itself rather than trying to impose preconceptions on it. It requires an open and receptive state of mind and concern for the integrity of the object (Alford, 1989). In contrasting analytic and syncretistic attention, Ehrenzweig (1967) particularly had in mind the ways in which we respond to visual and other forms of art, closing in analytically on detail (a brush stroke, a musical phrase) and then 'standing back' to see or hear the far-flung emergent structures that produce the whole composition. In syncretistic mode, when an observer 'takes in' a painting or a theatrical 'scene', the pupils dilate and the gaze relaxes to allow the dedifferentiation required for a comprehensive view. 6

The alternation between analytic and syncretistic attention is necessarily involved in processing the huge quantity of information provided by film-based visual data. Hence the detailed analysis that preceded the writing of the scenic composition involved scrutinising the transcript, a clip-by-clip panel interpretation of small segments of film data, an examination of data related to Darren's offending, and biographical information held on file. By the time Lynn came to write the composition, she had been steeped in this material and was very familiar with the case and its societal context. Her initial analysis, however, failed to convey the idiomatic effect of Darren or her experience of his interaction with Bob against the background of the educational and youth justice systems. Only by 'standing back' and allowing the scene as a whole to appear to her syncretistic 'mind's eye' was she able to produce the scenic composition.

It is relatively easy as social scientists to account for how we understand the social structures in which Darren is embedded, but more difficult to account for the quality of his relation to them. If such an account arises from an attunement that draws on the researcher's unconscious awareness, what kind of unconscious is at play? Ehrenzweig (1967) considered syncretism to be libidinally driven, impelled by phantasy and - here the influence of Bion (1962) is crucial - enabled by reverie. Syncretistic perception implicates the mind and body of the perceiver, and the object thus perceived bears his or her idiosyncratic imprint.

The scenic composition is an artful representation that does something similar. Its virtue is that it renders the researcher's experience of the object in a form that can be considered (and critically analysed) by others. The relational and structural properties of the 
whole inform the aesthetic of the scene and allow the researcher to register and render its emotional texture. The act of scanning presumes 'negative capability', the ability to apprehend open structures without focusing on detail or foreclosing on meaning. Bion's use of the concept of negative capability brought together the artistic and clinical psychoanalytic attitude. He famously borrowed the term from a letter written by the poet John Keats (1817) to his brothers after seeing a Shakespearean play - describing the concept as a quality of attention that Shakespeare's work both epitomised and evoked: 'that is, when a man is capable of being in uncertainties, mysteries, doubts, without any irritable reaching after fact and reason' (cited Bion 1970 p.125). In the clinical setting, negative capability indicates the capacity of the analyst for reverie, in which the patient is beheld 'without memory or desire' (Bion 1970 pp.30-36) as the unconscious of the analyst is attuned to the unconscious of the analysand (thus creating the conditions for what would nowadays be called unconscious intersubjectivity). According to Ehrenzweig, this quality of attention allows a perceptual awareness open to primary process. The unconscious of the observer is not overridden by cognitive analytic activity.

In such ways Lorenzer's account of scenic understanding chimes with other psychoanalytical writers, all giving clues to how to approach reflexivity in psychosocial methods. Together they help in theorising the role of the visual in empirical research, where and how to preserve experience-nearness in research, how to work with complex wholes rather than fragmenting data to the point of loss of meaning, and how to use the full resources of researcher subjectivity and societal awareness in understanding participant experience. We bear these elements in mind, alongside some of Lorenzer's key concepts, as we analyse the foregoing scenic composition.

\section{Construing Provocations in the Text}

The manifest meaning of our text could run as follows. The interaction between Bob and Darren involves a number of permutations of teenager-adult authority relation. Bob is initially in pedagogic mode while Darren is passive and dependent, adopting postures that make him appear slightly shrunken, as if he is reluctant to occupy fully even the small space available to him. In contrast, Bob appears larger than he actually is. Yet the task they are bent on demands a degree of equalisation if Darren is to participate enough to feel he has a hand in the construction of a poem. The situation is complicated by the fact that the authority relation is 
institutionalised. Bob is employed on a per-session basis by the Youth Justice Agency. He endeavours to maintain a degree of liminality, somewhere between the YOT and the street; yet his assertiveness and Darren's pliability - followed by an attempt to turn the tables - reflects a tussle between them. The interpersonal tension signals a primary societal tension of the Youth Justice System: on one hand, it pursues a rehabilitative ideal that aspires to recognise Darren's agency and subjectivity; on the other, it is charged with reforming his behaviour. As researchers, we can consciously register the societal in the various permutations of teenageradult authority relations enacted in this encounter. Whilst intersubjectively specific to the actors, they are produced by societal ascriptions of status, cultural tropes of adolescent rebellion, performative scripts of delinquent and respectable masculinity, and the power relations implicit in the youth justice system.

If we can understand that much through an experience-near portrayal and a reasonably holistic perspective such as would be afforded by a phenomenological analysis, how can we approach the text's latent meaning? Lorenzer suggests taking a cue from emotional responses to the scene that register as 'provocations' (see Bereswill et al, this issue). For him, the idea of a provocation in a text, once registered in the emotional response of the (data) analyst, brings together the subjective fantasy and the concrete social reality: 'texts are not ... empty formulae to be filled, their provocation lies in a quality present in the text itself' (Lorenzer, 1986, pp. 28-29). Here, Lorenzer is not positing the (cultural or social) analyst's subjective ideas and fantasies as separate from or undisciplined by 'concrete social reality'; he is attempting to think the psychological and the social together. The implication is that, since the provocation's significance 'is not restricted to the individual,' it can be understood as collective in the sense that subjective fantasies draw on the necessarily social quality of collective experience through the scenic interaction forms that are evoked in current interactions.

For us, a linked series of provocations stands out in the scenic composition (provocations that are all but lost in the transcript): the moment when the stressed and still submissive Darren puts his hand down the front of his trousers - apparently for comfort; Bob's gaffe, 'What'll you be when you're not clever?' (awkwardly retrieved but not before being indignantly registered by Darren); and Darren's exit from the room, as Bob tries to hold him 
long enough to establish some closure on the poem. These instances are inextricably linked within the unfolding scene, and each becomes more intelligible in the light of the other.

There is something childlike about Darren's masturbatory moment. A version of adult masculinity is at stake. He is being asked to perform in a situation that, to judge by his shifting and shuffling, is uncomfortable for him. He is being invited to complete a task in a medium (language) where the education system that has excluded him for his poor behaviour has deemed him a failure. In the office, Darren is being filmed by university-based researchers also presumably clever - who represent an educational provision that he is unlikely ever to access. The pressure he is under and the overt reason for his comfort-seeking gesture are easy enough to understand. To engage him in creative writing is to foreground the implicit stigma of ineducable, destructive working class hoodlum. Bob has homed in on this issue by picking up Darren's 'not clever' self-description and does not let go, even though its potential sensitivity makes it a high-risk strategy. A great deal is invoked in the word 'clever', which refers not only to educational attainment. Also at stake is the cleverness admired by Darren's peers: craftiness, living on one's wits, getting by against the odds - the kind of cleverness for which he might still gain respect.

Bob's overtly respectful and encouraging 'pedagogy' is betrayed by the slip 'when you're not clever'. Something in these words is being camouflaged. By virtue of that stumble Bob inadvertently transmits a societally registered anxiety that many of us are liable to share. Indeed, it pinpoints the unease we (the authors) feel on watching the interaction. For instance, Lynn found herself agreeing with Darren's 'I'm not clever' and therefore reluctantly identifying with Bob's gaffe. She squirmed inwardly. This response led her to consider those instances of humiliation that might have left their traces on Darren, perhaps in the form of embodied shame not consciously experienced. She reflected as follows:

To construe the unsymbolised dimensions in the scene, I bring to bear both a personal and a culturally embedded understanding of the nature of developmental conflicts. The re-enactment of early separation struggles through adolescent challenges to authority are emotionally familiar to me personally as well as cognitively understood; so too are the anxiety of demonstrating competence and finding a place in the cultural order. I feel 
pained at Darren's shaming, anxious at his meagre cultural resources and

far from convinced that he will get by in the world of employment.

Darren's self-abasing, 'I'm not clever' is perhaps a clue to the nature of the specific interactionform that may have been shaping his interaction with Bob.

According to Lorenzer (1986), scenic experience is inscribed in the form of engrams in neuronal pathways (the registration in the body-mind of what Freud referred to as memory traces - see Bereswill et al, this issue). Because of this inscription, an interaction in the present, such as Darren's positioning as 'not clever' in relation to Bob, necessarily evokes interaction forms from the past.

Engrams are susceptible to activation or modification with each new experience and give rise to habitual patterns of interaction. Yet they are forever evolving in dialectical relation with events and relations that re-enforce, or confound and otherwise modify, the prior experience - in this case the sense of shame. The visceral and unexpected nature of the researcher's 'squirm' - a kind of somatic countertransference - alerts us to the embodied or engrammatic register of experience. It draws on unspeakable reservoirs of shame, socially meaningful yet unique to the individual in whom they are inscribed. The discomfort enacted here in all its unwelcome suddenness has belonged elsewhere. At the same time the shame in question is at work in collective processes of projective denigration: the statement, 'I'm not clever', points to an internalisation on Darren's part of the stigma that in the UK attaches to young males from the so-called 'underclass': ineducable, incorrigible, unemployable. That we discover ourselves to be complicit in those assumptions potentially opens up awareness of the degree to which young men like Darren hold an extruded and disavowed destructiveness on behalf of society. Yet, rather than stimulating a sense of shared responsibility, they trigger societal moral panics fuelled by media stories of antisocial behaviour and statistics on male educational underachievement. In the tabloid imagination that we may all in some degree share, young men like Darren are the source of intractable social ills: lone motherhood, poverty, crime and disorder.

While engrams are biographically unique and therefore particular to the subject, the interaction form condensed in the meanings of 'clever-not clever' is not located exclusively in Darren, nor specifically in the interaction between him and Bob, nor in the researcher-viewer 
of this visual text. It exists among all these as an expression of the collectively held societalcultural experience that is not always available consciously. The polyvalent nature of the interaction form gives clever and not clever their meanings. Lynn's reception of Darren's 'I'm not clever' is an example of her participation in processes, partially unconscious in nature, that, despite their biographical specificity, are also shared. The squirm indicates latent meaning that is not readily or fully available to symbolisation (see Bereswill et al, this issue).

The unconscious unsymbolised material in play raises questions about what in Darren and Bob's encounter is available consciously and to whom? Bob's slip suggests that his feelings about Darren's stupidity are emerging into conscious speech despite suppression of such an incorrect idea (Freud's concept of parapraxis). In Darren's case, his claim ('I'm not clever') indicates that, despite its humiliating aspect, he is able to symbolise at least some of this experience of himself. His admission that he cannot read, however, and then his hovering on the verge of flight point to a measure of discomfort and imply that something of the experience remains troubling for him. In Lorenzerian terms, this enactment of inexpressible unease suggests the presence of an interaction form that has either been subject to language destruction or partially barred from symbolisation (see Bereswill et al, this issue). It is possible, then, to view Darren's claim as defensively fending off a configuration of scenic experience related to the shame of illiteracy and exclusion from school. Indeed, his slump seems to convey a helpless incapacity that becomes painfully clear when he is asked to read.

Although the social stigma of illiteracy and exclusion from school go a long way to explain the dimensions of Darren and Bob's encounter that seem to be troubling and unsymbolised, we also need to take into account a biographical issue that appears to have been closely bound up with Darren's expulsion from school. It seems possible that a key traumatic experience in Darren's life was his father's death. We know from his elder brother, also interviewed, that their Dad died when they were babies (the brothers both live with their Mum, although she kicks them out repeatedly for bad behaviour). Significantly, neither brother knows the details of their father's death - they have not been told and they don't ask. Although we cannot be sure, it is possible that Darren may never have had the opportunity fully to digest or emotionally assimilate his experience of loss. 
In Bion's (1962) theory of thinking - one that has interesting parallels to Lorenzer's the seemingly unsymbolised nature of the fact of his father's death would be understood as one in which Darren's sense impressions and emotions from the time remained as unprocessed elements: 'not felt to be phenomena but things in themselves ... not so much memories as undigested facts' (pp. 6-7). For Bion, if they are to be available for symbolisation, elements of raw experience need to be 'processed' (alpha-function, in Bion's terminology). This 'makes the sense impressions of the emotional experience available for conscious and dream thought' (pp. 6-7). In Bion's theory, a mother's state of 'reverie' - her (variable) capacity to receive, digest and detoxify her infant's unthinkable communications (projective identifications) and return them in bearable form - was the basis for his concept of containment and fundamental in his theory of thinking. Bion argued that the containment function that originally belongs to the mother or other adult caregiver is, all being well, successfully internalised by the developing child so that the capacity to contain becomes part of the child's own mental apparatus, permitting thinking about impinging realities that might otherwise be frustrating and unbearable. Here, knowing is a mental function with emotion at its core. Whatever Darren went through when his father died would have been painful to symbolise (and, in any case, he was too young for words); either way it sounds as if his mother could not act as a container, to help him think, but could only unconsciously communicate that words about this experience were out of bounds. For Bion, the experience thence transformed into 'nameless dread'.

Significantly, Darren's exclusion from school and his branding as a racist appear to have been occasioned by an insult that tapped his unsymbolisable feelings about his Dad, and was enacted in fighting back. He was excluded from school for 'being racist mostly' and told the interviewer:

Well there's a lot of Asians there and that were mostly why, 'cos they were calling me 'white scruff' and, er, calling stuff about your Dad and that, so just went mad one time and the teacher tried to stop me and like, did ... some ... bad stuff so it kept on adding up all the time and they like kicked me out.

There is a noticeable erasure of the pronoun ' $l$ ' in two places in that account when Darren moves from the first insult, white scruff, to the second, stuff about his Dad. 
While Darren's feelings associated with being 'not clever' - not clever enough, for example, to read his own poem - can help to explain his desire to flee the room, we need also to explore what might have kept him there for so long. It seems possible that something hopeful may also have been going on in Darren's encounter with Bob. It could be that the counterpoint to flight is the promise of symbolisation itself. Lynn's reflection on this question is as follows:

I am gratified that this 'destructive illiterate' accepts the unlikely challenge of cooperating in 'creative writing' and it seems to me that he is surprised at himself and pleased with his small achievement, just as I am pleased for him. After all, the poem, poor as it is, is crafted from his words. Because of my own commitment to the power of words, I like to think it is this, as well as the need to overturn Bob's authority, that allows him to assert himself and reclaim self-respect. I am satisfied that in doing so Darren shows a kind of cleverness after all

Perhaps Darren has agreed to play with the idea of 'cleverness' and its possible meanings for him. The creative writing session, edgy as it is, is a space where he is being invited to experiment with self-representations and where there is no predetermined outcome. Bob provokes Darren within limits and comes across as a largely reliable, empathetic, containing figure who is generally able to hold the frame of the session and foster conditions in which Darren can explore who and what he is. In Winnicott's (1971) terms, Bob initially creates the conditions for a potential space in which Darren can discover for himself what kind of cleverness he can lay claim to. The potential space, according to Winnicott the origin of the entire cultural domain, lies in between that which is internal to the individual and that which has the quality of externality. Its importance for the developing infant and for all of us in later life is that it allows us to play with the relation between inner and outer reality.

Winnicott argued that the prototypical potential space where the infant can lose itself in play is presided over by the containing but nonintrusive mother. Beyond infancy, potential 
space remains a site of illusion in which any habitual sense of the boundaries between inner conception and outer reality are provisionally suspended. The individual can thus rehearse imaginatively his or her relation to the cultural domain through symbolisation. There are some significant parallels between Winnicott's and Lorenzer's conceptions of symbolisation insofar as the symbol is both a subjective creation and a cultural artifact it has social significance by virtue of its position in a collectively shared symbolic system, but it has significance for the individual insofar as it gives form to an inner, somatically grounded desire. Winnicott described the happy moment of conjunction between inner and outer reality in symbolisation when the child 'discovers' what is there to be found and in that act inserts himself creatively into a shared cultural domain.

The implication is one that Lorenzer (1986) elaborated: for the symbol to retain both its personalised resonance and its ability to connect the individual to a linguistic community, it must remain sensuously and affectively grounded; to avoid the rule-bound desymbolisation of cliche it must be continuously refreshed and discovered anew. The vehicle for this animation of linguistic symbols - the means whereby they are bound to action and sensually regrounded - is language games (see Bereswill et al, this issue). Language games allow for a multiplicity of meanings in the conjunction of discursive and presentational symbols (for the latter, see Langer, 1942), and in their open-endedness allow us to participate in a system of shared meaning, although the rules can never be known perfectly in advance and will only become clear in their future use.7 Although Winnicott did not consider language games explicitly, his work implies that, without some ability to inhabit potential space, to retain an illusional capacity that allows the subject to act 'as if' the emergent rules of game will make sense, the creativity of linguistic communication would be foreclosed. Some tolerance of the tension between an inner conception and culturally sanctioned symbolic system is needed so that one can play the game and sustain the illusion that the outcome can in some measure conform to one's intentions whilst accepting it will always confound them.

\section{Triangular Space, Mental Space}

There is, perhaps, an additional dimension to what keeps Darren in the room and, thereby, in relation to Bob. Three parental figures - his Mum and two authoritative males - were invoked in answer to Bob's question asking Darren to name three clever people: clever because they 
can tell him what to do or show him how to do clever things. Darren affectionately accepts Mum's natural authority. Al, the workshop leader, represents another world that Darren has so far failed to access: well-paid (in Darren's fantasy), skilled, responsible, working-class masculinity. It is, however, with Bob, whose cleverness is as bearer of language and culture ('cos you can write poems'), that Darren struggles. Bob evokes fascination but also defiance. The data sequence ends with Darren's assertion of independence. He gets out fast, neglecting to take with him - and thus keeping at bay - the poem, the very thing they have created between them.

Both Winnicott and Bion emphasised the early role of the maternal in thinking and creativity, but it is through oedipal theory that the paternal has been theorised, emphasising the father as the third term through which dyadic experience is challenged and potentially transformed. The post-Kleinian tradition has developed oedipal theory in relation to thinking, emphasising the emergence of mental or triangular space (Britton 1993, 1998). For Britton, the paternal principle forms a triangle in which the child is placed in a position qualitatively different from the one that obtained in the mother-child dyad. Having access to a relationship between two people that exists independently of the child itself, it can experience the quality of that relationship from outside, as witness not participant. It can then imagine that there is more than one position to be known from and can imagine that its relationship with either of the others can be known by the third. Thirdness then signals the expansion of mental space, the ability to see oneself in relation to others from different vantage points and imagine how others might see you. It is the basis of the ability to make full use of a symbolic cultural order. If Bob occupies the position of the third in relational configuration with Darren's mother, it seems possible that he helps Darren to produce thirdness in the shape of a cultural object - a poem (Froggett, 2008) - in which Darren is able to envisage that things might be different: 'I'm not clever, but not forever'.

\section{Conclusions}

We began this essay by noting the challenges we have faced in representing and analysing qualitative, particularly visual, data both psychosocially and in ways that preserve its experience nearness and the complexity of the whole. Drawing on post-Kleinian concepts of using emotional experience to think, syncretistic perception and potential space, we had 
already travelled a long way from the focus on the manifest meaning of words that has largely dominated qualitative data analysis.

Our exploration of Lorenzer's concept of the scenic led us to the idea of writing a 'scenic composition', based on a methodology of working through the scenic understanding of a researcher to capture meanings that lie in between concrete social reality and subjective fantasy. The main theme that emerged from this exercise was a scenic understanding of Darren's claim to being 'not clever', as it was expressed in the interaction between him and Bob. Our interpretation suggests that the scene that emerged between Darren and Bob drew on the biographically specific (for example, Darren's behaviour at school, his Dad's death when he was young, his inability to read), the societal and collective dimensions of unconscious processes (the shame of illiteracy, families without paternal figures, the fear of ineducable youth) and the manifest forms of cultural life (school exclusion, maternal responsibility and authority, the Youth Offending Team project, among others).

Our interpretation also suggests the possibility that Darren's creation of a poem in interaction with Bob produced a modified scenic experience, for example, of his father or of not being clever. His scenic experience of being not clever would have arisen from interaction forms that had built up throughout his life, triggered perhaps by his unsymbolisable experience around his father's death, but made and remade in the particular familial, locally inflected scenic experiences of his encounters with school and the world of symbols generally. With Bob, we suggest, something became further symbolised in the poem. Darren was now participating in the cleverness of writing poems by providing the words, while Bob had added some rhythm, rhyme and scansion, playing with Darren's words creatively and capturing them in written form. All this was apprehended through the research analyst's scenic understanding, an understanding inflected by her biographically specific experience and the way she therefore construes the manifest and latent forms of cultural-societal life.

One of the difficulties for psychoanalytically informed psychosocial methodology has been to deploy a version of unconscious processes that does not reduce to an individual unconscious. In this regard, post-Kleinian accounts, informed as they are by the concepts of projection, introjection and projective identification, have proved particularly useful, not least in rendering our understanding of unconscious dynamics radically intersubjective. The 
ontological base of these dyamics, however, is often limited to the dyadic, triadic and group. In contrast, Lorenzer offered a more materialist treatment of the societal and cultural. Our use of Lorenzer has, it seems to us, helped us to talk about cleverness, education and the youth justice system in ways that do not reduce to a conception of the societal that is dualistically split off from the psychological.

The principle of unconscious intersubjectivity has also been basic to our methodological attempt to go beyond a sociological notion of reflexivity (Hollway, 2010). A psychoanalytic epistemology based on transference and countertransference is premised on the unconscious intersubjective movement of ideas (from patient to analyst and analyst to patient). Being in excess of the current situation because they draw on archaic relational patterns internalised by each of the participants (Lorenzer's interaction forms), these unconscious ideas transform the meanings that are communicated.

The idea of the unconscious as coextensive with the unsymbolised (and therefore including what is potentially unsymbolisable) and formed intersubjectively is (at a stretch) common to both Lorenzer and the post-Kleinians. By 'at a stretch', we mean that Lorenzer appears to have used the concept of the unconscious with different emphases (ranging from something like the unconscious intersubjectivity described above to a 'societal-collective' unconscious or to something more like Freud's repressed unconscious). Bion made a clear distinction between beta elements (the not-yet symbolised) and experience that has been dreamed/thought and then repressed. Although we consider these alternative conceptions of the unconscious are not mutually exclusive, the frame afforded by our focus on research methodology makes more appropriate and more available the idea of a dynamic, always fluid movement among conscious, preconscious and unconscious modes of doing psychological work with experience (Ogden, 2004).

The Lorenzerian and post-Kleinian tradition also have in common the idea of unsymbolised experience laid down in corporeal form to provide a unique reservoir for meaning if and when intersubjective conditions and language render this formerly unsymbolised material available for thinking and expression. There are differing conceptualisations of this unsymbolised experience, each with their own inflection - primary process, beta elements, engrams - and a detailed discussion of their distinctiveness is beyond 
the scope of this paper. We wish to emphasise, however, the potential creativity of this sensual and emotional realm, when and if it can be engaged imaginatively.

At this point Wendy writes, 'I find myself wishing that Darren had taken the poem with him and wanting to know if he returned for a further session with Bob and laid claim to this or a later poem by taking it with him'. My reparative wish has been enabled by the idea that Darren's scenic experience has been modified through sharing his words about being not clever, but not forever. It seems that Lorenzer's concept of the scenic can not only provide a method for us that is non-reductively psychosocial, but also explain in a new language why an arts-based project might be a helpful intervention for offending youths.

\section{About the Authors}

Wendy Hollway is Professor of Psychology at the Open University. She draws on psychoanalysis to furnish principles for a psycho-social methodology. She is in the process of writing a book drawing on Wilfred Bion's theorisation of knowing, thinking and emotional experience. 'Mothers' Knowing/Knowing Mothers' is based on research data from women as they become mothers for the first time. This and related work is supported by an Economic and Social Research Council Fellowship

Lynn Froggett is Professor of Psychosocial Welfare and Director of the Psychosocial Research Unit (www. uclan.ac.uk/pru) at the University of Central Lancashire. She draws on psychoanalysis. social science and the humanities to develop psychosocial research methods. A particular current interest is in the development of 'experience- near' and 'practice-near' approaches to researching interventions in health, social care, youth justice and the socially engaged arts.

\section{Notes}

1 The data were collected by Alan Farrier and Konstantina Poursanidou at the Psychosocial Research Unit, University of Central Lancashire.

2 Our initial plan was to include two data examples, one from each of our (rather different) observational methods. This approach turned out to provide too much material, so here we use an example from Lynn's research. Wendy's example will figure in a future publication.

3 See Psychoanalysis, Culture and Society 13(4), 2008 for an introduction to this tradition.

4 This phrase might be specific to local dialect, or Darren might have made it up. We understand it to mean having a good time, possibly while high.

5 Detailed referral and assessment forms are held on file in the YOT and are updated as young offenders move through the youth justice system. These files were made available to the research project. 
6 Although Ehrenzweig's primary interest was in the appreciation of art, he argued that these alternating forms of attention characterise any creative search including those of mathematical theory and - intriguingly - language games. Lorenzer considered the ways in which language games in Wittgenstein's sense contain the scenic in language.

7 For this reason Ehrenzweig (1967) considered that the language game demands a syncretistic view, which facilitates discernment of emergent structures.

\section{References}

Alford, C.F. (1989) Melanie Klein and Critical Social Theory: An Account of Politics, Art and Reason Based on Her Theory. New Haven, CT: Yale University Press.

Bion, W.R. (1962) Learning from Experience. London: Maresfield.

Bion, W.R. (1967) Second Thoughts. London: Maresfield.

Bion, W.R. (1970) Attention and Interpretation. London: Maresfield.

Bollas, C. (1989) Forces of Destiny: Psychoanalysis and the Human Idiom. London: Free Association Books.

Bollas, C. (1992) Being a Character: Psychoanalysis and Self Experience. London: Routledge.

Britton, R. (1993) The missing link: Parental sexuality in the Oedipus complex. In D. Breen (ed.) The Gender Conundrum. London: Routledge, pp. 82-94.

Britton, R. (1998) Belief and Imagination. London: Routledge.

Ehrenzweig, A. (1967/1970) The Hidden Order of Art. London: Paladin.

Farrier, A., Froggett, L., and Poursanidou, K, (2009) Offender based restorative justice and poetry: reparation or wishful thinking? Youth Justice 9(1): 63-78.

Froggett, L. (2007) Arts based learning in restorative youth justice: Embodied, moral and aesthetic. Journal of Social Work Practice 21(2): 249-361.

Froggett, L. (2008) Artistic output as intersubjective third. In: S. Clarke, H. Hahn \& P. Hoggett (eds.) Object Relations and Social Relations: The Implications of the Relational Turn in Psychoanalysis. London: Karnac Books, pp. 87-111.

Froggett, L., Farrier, A., and Poursanidou, K. (2007) Making sense of Tom: Seeing the reparative in restorative justice. Journal of Social Work Practice 21(1): 103-117.

Geertz, C. (1974) From the native's point of view: On the nature of anthropological understanding. Bulletin of the American Academy of Arts and Sciences 28(1): 26-45.

Hollway, W. (2009) Applying the "experience-near" principle to research: Psychoanalytically informed methods. Journal of Social Work Practice 23(4): 461-474.

Hollway, W. (2010) Conflict in the transitions to becoming a mother: A psycho-social approach. Psychoanalysis, Culture and Society 15(2): XX-XX.Keats, J. (1817, 2009) Letter to brothers, http://www.mrbauld.com/negcap.html, accessed 21 December 2009.

Langer, S.K. (1942, 1990) Philosophy in a New Key: A Study in the Symbolism of Reason, Rite, and Art. Cambridge, MA: Harvard University Press.

Lorenzer, A. (1977) Sprachspiel und Interaktionsformen: Vorträge und Aufsätze zu 
Psychoanalyse, Sprache und Praxis. Frankfurt/M.: Suhrkamp.

Lorenzer, A. (1986) Tiefenhermeneutische Kulturanalyse. In: A. Lorenzer, (ed.) KulturAnalysen: Psychoanalytische Studien zur Kultur. Frankfurt/M.: Fischer, pp. 11-98.

Ogden, T. (2004) On holding and containing, being and dreaming. International Journal of Psychoanalysis 85: 1349-1364.

Winnicott, D.W. (1971, 2005) Playing and Reality. London: Routledge. 